\title{
Educational Innovation Project for the Creation of Didactic Materials for Students With Special Educational Needs: An ApS Experience in Higher Education
}

\author{
Tamara Díaz \\ Comillas Pontifical University \\ Esther García \\ Comillas Pontifical University \\ Marta Hernández \\ Comillas Pontifical University
}

\begin{abstract}
The Service-Learning methodology has an important role in the training of future teachers by connecting formal learning with the reality of an educational center. Based on this methodology, the project was proposed as an interdisciplinary didactic proposal, within the university environment, between the subjects of Psychomotricity, and Early Care and Educational Innovation, aimed at improving the quality of initial training. To this end, we have worked with the Early Childhood Education centers of the Montemadrid Foundation, aiming that university students contribute to the training of students with special educational needs attending these centers, through the creation of adapted didactic materials. This innovation project has achieved its objective of developing the basic student skills, helping to consider in school practice the principles of inclusion and normalization in a real environment; this has strengthened the university-school relationship, as well as contributed to a greater awareness of future teachers towards inclusion, as a central principle of any educational proposal.
\end{abstract}

Keywords: interdisciplinary approach, teacher training, 21st-century skills, quality education, servicelearning methodology, active methodologies, college school cooperation, teacher collaboration

\section{INTRODUCTION}

This Aprendizaje-Servicio (ApS, Service-Learning) project arises after reflecting on the methodology used in the subject Psychomotricity and Early Care - compulsory for future Infant Education teachers -, taught at the Faculty of Human and Social Sciences of the Comillas Pontifical University. As a result of this reflection, the need to help students to understand and apply the contents of the subject, through experiences that facilitate active and meaningful learning, is assumed. 
To this end, a collaboration proposal was made to the guidance counselor of the Montemadrid Nursery Schools, to allow university students to contribute to the improvement of the quality of education of students with specific educational support needs, through the creation of adapted didactic materials. In the final stage of the project, the teacher responsible for the subject of Educational Innovation joined the experience, given the convergence of this subject with that of Psychomotricity and Early Care and intending to provide a systemic framework of reflection to the experience of ApS, and provide the project with an interdisciplinary character within the university environment. This articulation between subjects will be reinforced, with joint planning from the beginning, in the project being developed during the 2018-2019 academic year.

The coordinated work and constant collaboration between different professionals throughout the past 2017/2018 academic year have resulted in the experience presented here.

\section{GENERAL DESCRIPTION}

Our Service-Learning experience is conceived as an interdisciplinary didactic proposal that ultimately seeks to improve the quality of the initial training received by future teachers. The temporal convergence between the subjects of Psychomotricity and Early Care and Educational Innovation has allowed us to design an innovation project that, based on the Service-Learning methodology, favors the university-school relationship, and facilitates the development of the basic competencies of future teachers and their sensitivity to inclusion, as a central principle of any educational proposal.

\section{FIGURE 1 \\ MATERIAL FOR PINCER GRASP (FINE MOTOR SKILLS): PRE-WRITING}

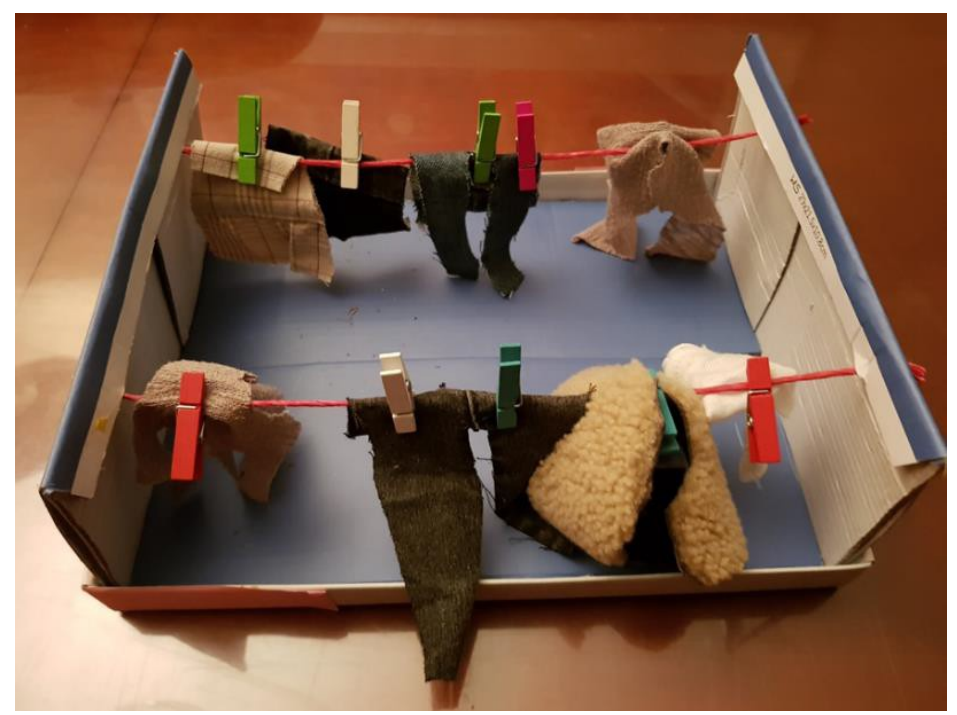

Materials prepared by Y. Castro Salamanca, I. Garcia Iborra and C. Gomez-Aenau Botas ( $4^{\text {th }}$ dual grade primary and infant education)

The purpose of this cooperative learning project has been the creation of didactic materials for students with specific educational support needs, attending the E.I Conde de Elda and E.I Adela Abrines of the Montemadrid Foundation. We emphasize that, from the university environment, the objective is not only to elaborate the materials but that these serve as the axis so that, in the process, the students understand the concepts and procedures and it is possible for them to reach the competences that we want them to develop. 


\section{PARTICIPANTS}

Two groups of students are participating in the project, from the 3rd year of Infant Education and the Double Degree of Infant and Primary Education, and from the 4th year of the Double Degree of Primary and Infant Education. The target audience of the material to be elaborated by the university students are students of two nursery schools (E.I Conde de Elda and E.I Adela Abrines) of the Montemadrid Foundation, schooled in the ordinary modality with support, or one of the TEA classrooms of the schools. Given the characteristics they present, it is considered advisable to use didactic resources adapted and personalized to their needs.

As indirect beneficiaries, reference can be made to the Educational Community as a whole insofar as it is a work proposal that requires the articulation of various actors and from which it is possible to identify broad positive effects (families, teachers...).

\section{IDENTIFIED NEEDS}

From Psychomotricity and Early Care, it is required to bring the student closer to the understanding of real practice, seeking the learning of theoretical foundations, professional strategies, attitudinal training, etc., essential for the work of any teacher of Infant education. The project is considered a significant learning experience, both because of its proximity to the interests of the students themselves and because it allows the practical exercise of functions that they will assume in the future (for example, the adaptation of strategies and resources to very diverse students), being more motivating because it is linked to its application in a real context.

FIGURE 2

\section{PICTOGRAMS: PRE-READING}

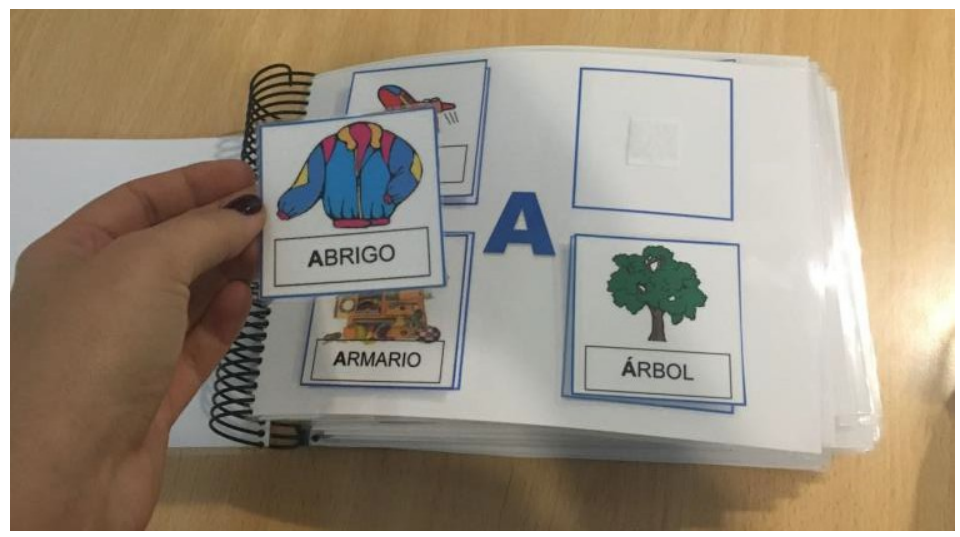

Material prepared by L. del Arco Talavera, B. Laso Pazos, L. López Fernández and M. Mansilla Sánchez.

The subject of Educational Innovation offers the framework from which to reflect on what constitutes the design and elaboration of an innovative work proposal. In particular, the need to carry out an adequate contextualization, theoretical foundation, and analysis of the reality as a basis from which to articulate an innovative educational project is highlighted. The identification of an adequate work schedule as well as the need to design, from the beginning, an evaluation proposal that accompanies the project from its origin, are other elements that are worked from this subject. Furthermore, special attention is given to the reflection and development of the students' critical capacity when it comes to pointing out which criteria make an educational project an innovation proposal. Since this is a Service-Learning project, many of the criteria 
that must be present for this purpose are identified from the beginning: its orientation towards improvement, systemic character, contextualization, usefulness, and real application, active and varied methodologies, as well as respect and attention to diversity in the classroom, among others.

From the university environment, the needs to be covered are formulated as follows:

- To develop the basic competencies of the students.

- Show students the need to present knowledge about the world and in reference to other disciplinary areas.

- To develop competencies related to information search.

- Review and analyze information relevant to each case.

- To favor the detection of developmental delays and alterations in children in the Infant Education stage.

- To facilitate the application of strategies that respond to specific learning needs presented by students in Infant education.

- Develop communication skills within a cooperative environment (identify and resolve conflicts in the group, distribute tasks and integrate results, commit to the work plan, deliver material on time, etc.).

- Strengthen university-school collaboration.

\section{SERVICE PROVIDED}

The project has brought benefits not only to our students but to the participants as a whole. Pertaining to the professionals of the educational entity -the teachers specialized in therapeutic pedagogy- who work directly with the target students, the previous years' experience has been an opportunity for them to develop professionally by sharing their acquired experience and knowledge with the university students.

For the students, the project has given them access to quality materials adapted to their level of development.

Finally, concerning the institution as a whole, participation in this experience has been a unique opportunity to make itself known and disseminate its model of attention to diversity.

\section{STUDIES IMPLEMENTED}

To favor the achievement of the aforementioned project objectives, the tasks are organized in different periods of four months. The following chronogram (Table 1) shows the sequence of the different phases of the experience: 
TABLE 1

DIFFERENT PHASES OF THE EXPERIENCE

\begin{tabular}{|c|c|c|}
\hline Project design and planning & $\begin{array}{l}\text { Compilation of material needs in each school } \\
\text { Explanation of the Project to the students } \\
\text { Organization of the tasks and the Timeline } \\
\text { Analysis of specific requests and allocation to each group }\end{array}$ & $\begin{array}{l}\text { July } \\
\text { September } \\
\text { October }\end{array}$ \\
\hline Project execution & $\begin{array}{l}\text { Workshop on the work with the ACNEES in nursery } \\
\text { schools and description of each case. } \\
\text { Design of materials } \\
\text { Review of materials } \\
\text { Material development }\end{array}$ & November \\
\hline Closing with the group & $\begin{array}{l}\text { Evaluation of results and learning } \\
\text { Delivery of materials to schools } \\
\text { Reflection on the experience and awarding of diplomas }\end{array}$ & $\begin{array}{l}\text { December } \\
\text { January }\end{array}$ \\
\hline
\end{tabular}

To facilitate students' learning, different ways are used.

\section{Classroom Training}

The course Psychomotricity and Early Attention allows students to learn about the work of the Infant Education teacher with students who present special needs in the first stages of development. Students handle assessment scales to detect alarm signs in development and can apply useful didactic resources to meet the needs of students with developmental delays or disorders.

\section{Non-Attendance Training}

Through the Moodle platform, students are provided with all the documents, experiences, periodic tasks, etc., that are considered appropriate to introduce, support, and consolidate the intended learning. Throughout the course, they can access the topics on the platform, with sufficient time in advance, as well as review them as many times as they wish.

The tasks chosen as non-face-to-face activities deepen the fundamental objectives, allowing the student to face the observation and analysis of the milestones of child development and its alterations or delays, and to express professionally -as future teachers- the assessment obtained and the recommended criteria for action.

\section{Meeting With Professionals}

A meeting or talk colloquium is held at the university, with the participation of professionals from nursery schools. Information is provided on the detection of developmental delays and alterations in children attending school during the academic year, and the need to adapt spaces and materials according to their difficulties.

Given that the classroom phase takes place between September and November, the timing of this activity takes place during the second half of October, to facilitate the preparation of the materials within the school period. 
FIGURE 3

MATERIALS FOR PINCER GRASP (FINE MOTOR SKILLS): PRE-WRITING

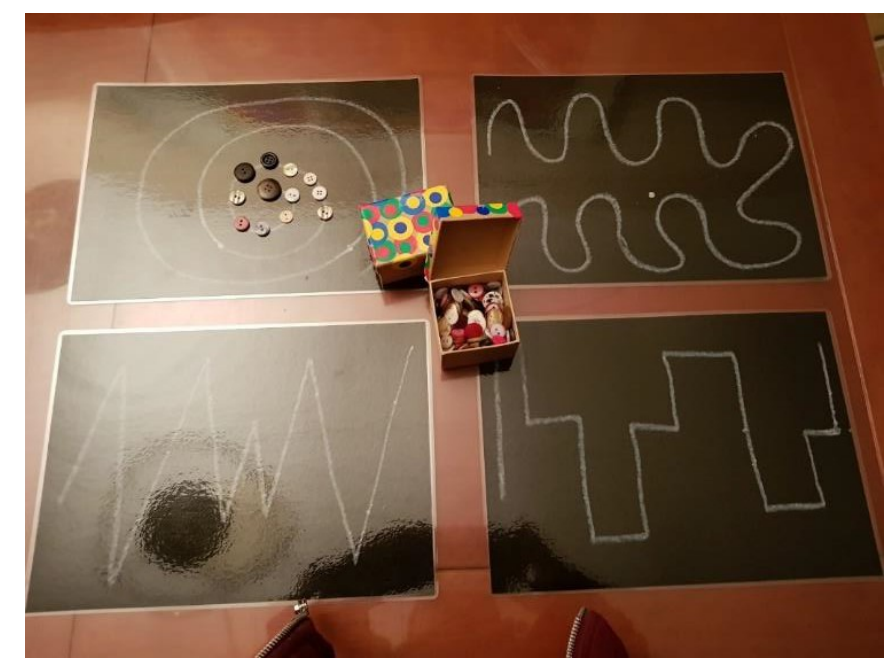

Materials prepared by Y. Castro Salamanca, I. Garcia Iborra and C. Gomez-Aenau Botas ( $4^{\text {th }}$ dual grade primary and infant education)

\section{Visit to the Nursery School}

Where the student to whom the resources are destined is enrolled once the didactic material has been elaborated by each work team. It is planned to allow the students to deliver the didactic resources they have elaborated, and to complete their self-evaluation in a real context, comparing the results with those they had projected. As in the previous case, the date of the visit is coordinated between the nursery schools and the teachers.

\section{Preparation of a Team Report}

Teamwork, in addition to enabling key competency learning such as the ability to relate and interact actively with others, offers many possibilities for thinking and analyzing ideas. It is especially useful for facilitating a change of perspective in the approach to the situations or cases to be addressed, making possible the creation of shared solutions with peers, through words or other mediators. Each team of students is organized to design and elaborate a project that should include the following sections:

- Job title.

- Rationale. The conceptual framework that frames the activity developed by the team is included here, using basic information about the disability, syndrome, or situation that generates special educational needs of the student for whom the material is intended.

- The most relevant information about the case chosen by each group will be provided by the Montemadrid Foundation Nursery Schools.

- Justification of the materials developed.

- The authors shall justify the choice of the type of support, its characteristics of use, manageability, hardness, flexibility... according to the previous section.

- Photographic list of materials with a brief description.

- The material resources created can be TEACCH (Treatment and Education of Autistic and Communication related handicapped Children) boxes, cards, collections of objects by categories, resources accessible on the web, stories with pictograms to work on autonomy, games to work on praxias, numbers, concepts, reinforcement of reading and writing, etc., etc.

- Presentation and evaluation of the project. 
The intended learning is to develop the competence in linguistic communication, both orally and in writing, about the development of the project and the creation of the materials. All students participate in the presentation to the group class, briefly presenting the rationale for their work, explaining the difficulties and capabilities of each case, and justifying the materials created and the process followed for its development (8-10 minutes maximum per group).

\section{FIGURE 4 MATERIALS TO TRAIN THE PINCER GRASP (FINE MOTOR SKILLS)}

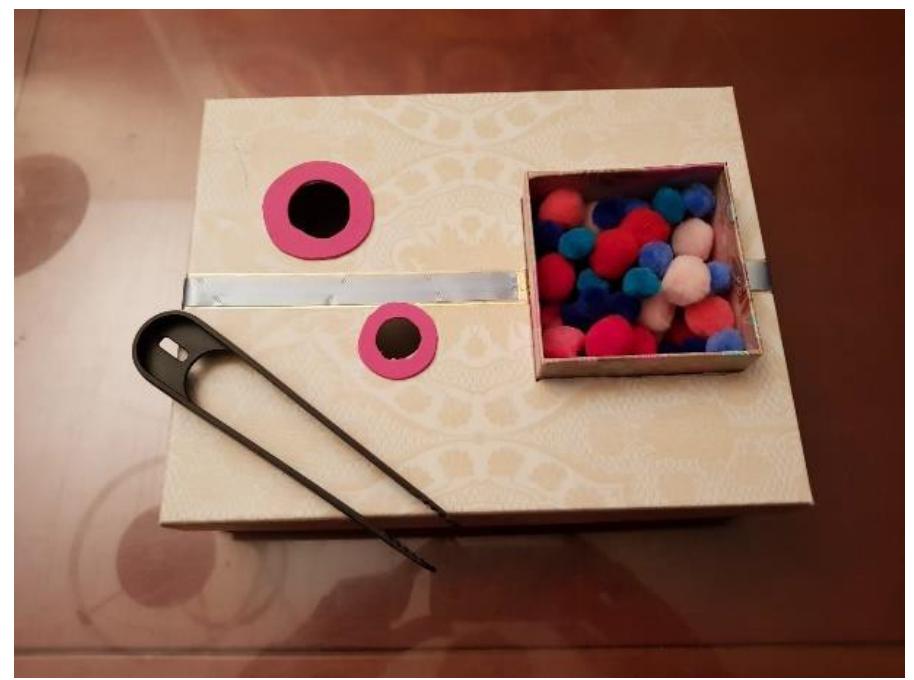

Materials prepared by Y. Castro Salamanca, I. Garcia Iborra and C. Gomez-Aenau Botas $\left(4^{\text {th }}\right.$ dual grade primary and infant education)

At the end of the experience, a questionnaire is applied to analyze the students' evaluations and the opinions of the nursery schools to decide whether changes are needed for the next school year.

Given the above, and following the needs and objectives defined for this ApS experience, learning is also achieved in the following two areas of work:

- Interdisciplinarity: the didactic methodology developed throughout the project has required an adequate coordination between subjects within the University, being this one of the aspects that is being reinforced in the project currently under development (the academic year 2018-2019). At the same time, this experience has allowed students to design activities that incorporate content from different areas of knowledge, breaking down the artificial barriers imposed by the subjects, integrating knowledge, and developing competencies that will later be fundamental in their work as teachers.

- University-school relationship: ensuring that students understand contents and can apply them in real contexts is another of the objectives that have been worked on in this experience. The design of didactic materials for "real" students, to be used in the centers where they attend school, not only favors the necessary university-school connection but also facilitates the development of basic competencies for future teachers through active learning with meaningful content. 
FIGURE 5

\section{PICTOGRAMS TO ENCOURAGE PRE-READING}

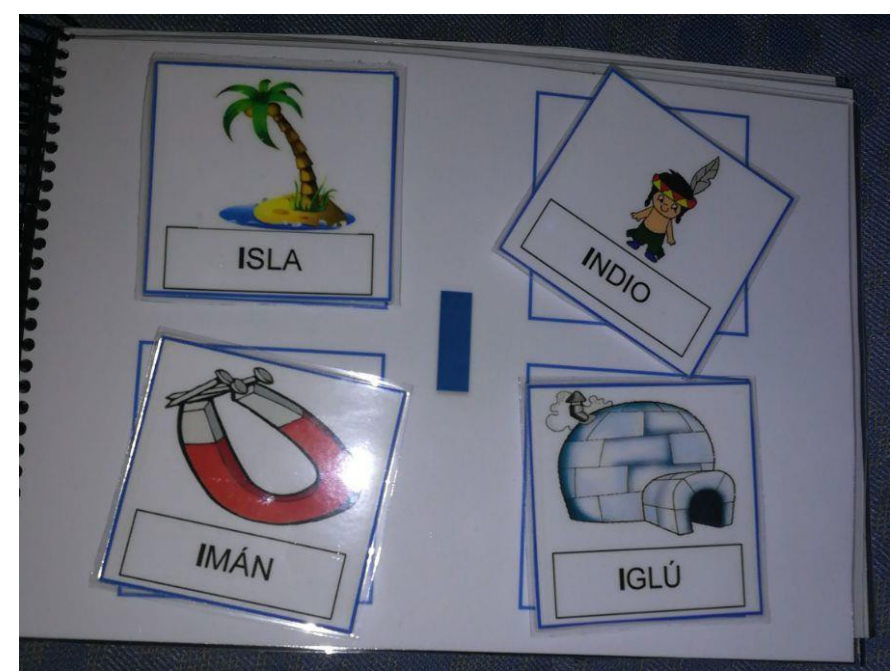

Material prepared by L. del Arco Talavera, B. Laso Pazos, L. López Fernández and M. Mansilla Sánchez.

\section{CONCLUSIONS}

To evaluate the degree of satisfaction of the nursery schools about the development of this project, Comillas Solidaria sent an evaluation questionnaire to the schools' guidance counselor, which was returned to us with the answers and opinions of the other professionals involved (PT teachers and directors).

The following general aspects are evaluated:

- The overall quality of work performed

- Punctuality

- Temporal adequacy of the project activities within the course.

- Adequacy of the project's activities to the children's ages

An assessment of the usefulness of the activity is requested:

- The usefulness of the information provided for decision making

- Usefulness to deepen in the topic addressed

- Saving time on a necessary activity from the school's point of view

The contribution of the participants (students, teachers, entity) in the final result of the project, the adequacy of the Project result to the initial expectations of the schools, the communication, and coordination with the teachers are valued.

All responses show a high degree of satisfaction. Therefore, we only highlight here the contribution of the nursery schools to our request for suggestions for improvement: What kind of difficulties have you encountered when participating in this Service-Learning program and how would you improve it?

The schools have offered us two reflections that we have considered relevant and that we will certainly take into consideration for future editions of the project:

- Improve the temporal organization of the actions included in the experience (visits, meetings with students at the university, delivery of materials to schools, etc.). The entity suggests the possibility of extending the collaboration until the end of the school year, which is impossible as the two subjects are four-monthly.

- Improve the dissemination or communication of the project internally and externally by the university. That is to say, to make the experience more visible among the rest of the students 
of the university, and to disseminate it from the university through channels that are within its reach.

- Extend collaboration to the four nursery schools of the Montemadrid Foundation, so that all students with special needs can benefit.

- Based on the evaluation of the reports and materials prepared by the students and as a result of our self-evaluation as teachers, a new work scheme has been designed, more complete and consistent with the premises of educational innovation, which has been implemented during the current 2018/2019 academic year.

Finally, it should be noted that the project, for its development, has contemplated the holding of periodic coordination meetings by the teachers (start, follow-up, and closing meetings throughout the four months schedule). Likewise, the students were asked to prepare a report on the work carried out, specifying the following sections:

- Beneficiaries of the project: to whom it is addressed.

- Substantiation: In addition to what was requested during the last academic year, the following will be taken into account standards if relevant to the project, as well as pedagogical theories, best practices, expert input (benchmarking), etc.

- Innovation: describe the innovation we want to achieve with the project by answering questions such as how is the project innovative, and how is it different from other similar projects, if any?

- Project Objective(s).

- Activities. Timing of activities: Extended Gantt chart with indicators, activity managers, etc.

- Project monitoring, control, and evaluation planning.

- Innovation evaluation.

From the university's perspective, after evaluating the learning achieved, the needs addressed, the products produced and the continuous and positive collaboration maintained between the educational entity and the university, we consider that this experience has achieved its purpose of facilitating learning by competencies in the training of Education students and that it has helped to understand and consider in school practice the principles of inclusion and normalization, in a real environment, thus contributing to the increase in the performance level of the students as well as their degree of motivation and involvement. For this reason, a new edition of the project is now being launched, which we hope will improve the one that has just ended.

Therefore, in this experience of constructive cooperation with the Montemadrid Foundation's nursery schools, both participants, students, and nursery schools, have benefited.

\section{ACKNOWLEDGEMENT}

Translated \& edited by American Publishing Services (https://americanpublishingservices.com/).

\section{REFERENCES}

Carbonell, J. (2012). The adventure of innovating. El cambio en la escuela. Ediciones Morata. Fernández, M., \& Alcaraz, N. (2016). Innovación educativa. Beyond fiction.Madrid: Pirámide. Marcelo, C., \& Vaillant, D. (2011). Desarrollo profesional docente: ¿Cómo se aprende a enseñar? Narcea, S.A. De Ediciones. 